\title{
Procedimentos de Expansão do Tópico em Diálogos Simétricos
}

\author{
Paulo de Tarso GALEMBECK \\ Universidade Estadual de Londrina \\ Fabrícia MENA \\ IC/UEL
}

Resumo: A primeira parte deste trabalho discute o conceito de tópico discursivo e suas característica. $\mathrm{Na}$ seqüência, são expostas as modalidades de expansão tópica: explicitação; exemplificação ou analogia; relações causais; opinião pessoal ou avaliação; objeção ou ressalva.

Palavras-chave: língua falada; diálogos simétricos; tópico discursivo; interação.

Abstract: The first part of this paper discusses on the concept of discourse topic and its characteristics. Afterward, are exposed the modalities of topic-expansion: elucidation; exemplification or analogy; causal relations; personal opinions or evaluations; objections or corrections.

Resumen: La primera parte de este trabajo discute el concepto de tópico discursivo y sus propiedades. Enseguida, son expuestas las modalidades de expansión tópica: explicitación; ejemplos o analogía; relaciones causales; opinión personal o evaluación; objeción o resalva.

\section{Preliminares}

Este trabalho discute os procedimentos mais comuns de expansão do tópico discursivo na interação simétrica. Para a consecução desse objetivo, a exposição é dividida em duas seções: a primeira é

\footnotetext{
* A versão reduzida do trabalho foi apresentada no IV Selesigno (Seminário sobre Linguagem e Significação), realizado em junho de 2004, na UEL.
} 
dedicada à conceituação de tópicos e à exposição de suas propriedade; na segunda, são analisados os três procedimentos mais freqüentes de explicitação do tópico: a explicitação, a exemplificação (ou analogia) e as relações causais.

O corpus do trabalho é constituído pelos inquéritos $\mathrm{n}^{\circ} 062$, 333, 343 e 360. Tratam-se de diálogos entre dois informantes (D2), cuja transcrição está publicada em Castilho e Preti (1987).

\section{O Tópico Discursivo e suas características}

\subsection{Conceito e característica do tópico discursivo}

O tópico discursivo pode ser considerado como um dos elementos essenciais na produção da fala e, por conseguinte, dos estudos de Língua Falada, por abranger dois aspectos, ou melhor, dois princípios fundamentais para o estudo da fala: o princípio fundamentador e o organizador. O primeiro deles relaciona-se com o fato de o tópico (aqui entendido como idéia, assunto, alvo) constituir o ponto referência ou, simplesmente, o referente (idéia, assunto, alvo), algo imprescindível para a elaboração da fala. O princípio organizador, por sua vez, diz respeito ao próprio desenvolvimento dos referentes. Antes de aprofundarmos estas idéias, é interessante observar o que dizem os autores.

Fávero (1999), ao analisar a coesão e coerência textuais, afirma haver, de modo geral, coerência no texto conversacional. Porém, por este último obedecer a processos de ordem cognitiva

muitas vezes se torna difícil detectar as marcas lingüísticas e discursivas dessa coerência, pois ela geralmente não se dá com base nas marcas, mas na relação entre os referentes: dai a importancia que a noção de tópico e de desenvolvimento dos tópicos na conversação vem adquirindo ultimamente. (FÁVERO, 1999, p. 93. Grifo nosso)

Marcuschi (1986), em sua Análise da conversação, ao discutir a organização do tópico, coloca que "só se estabelece e se mantém uma conversação se existe algo sobre o que conversar, nem que seja sobre futilidades ou sobre o tempo, e se isto é conversado". É a isso 
se refere Goffman, quando sugere que uma conversação é uma “interação centrada" (apud MARCUSCHI, 1986, p. 77). Brait também compartilha dessa idéia; em suas palavras, o tópico discursivo é "parte constitutiva do texto oral na medida em que os interlocutores só podem se relacionar a partir da presença desse aspecto" (BRAIT, 1993, p. 209).

Jubran et al (1993), por sua vez, acrescentam que a noção de tópico define, além da idéia de Goffman acerca da conversação como uma "interação centrada", o seu - da conversação - movimento dinâmico, fazendo do próprio discursivo "um elemento decisivo na constituição do texto oral, e a estruturação tópica serve como um fio condutor da organização discursiva" (JUBRAN et al., 1993, p. 360).

A partir dessas verificações, percebe-se que a noção de tópico está sendo elaborada segundo uma perspectiva discursiva, no âmbito do texto/discurso. O tópico é definido por Brown e Yule (1983) como "aquilo do que se está falando", mas ele (o tópico) só pode ser compreendido dentro do processo interacional, já que a interação interfere diretamente na seqüência tópica. Jubran (1993), em seu pormenorizado estudo acerca do tópico, estabelece essa convergência de atenção a um determinado assunto como reveladora do primeiro traço básico identificador do tópico discursivo: a centração. $O$ segundo traço identificador do tópico discursivo é o fato de este poder dividir-se em tópicos mais específicos ou de menor abrangência, que, contudo, mantêm entre si uma relação de interdependência, característica denominada organicidade.

A organicidade pode ser observada em dois planos: linear ou horizontal e vertical. O primeiro indica a relação entre os tópicos na linha discursiva, em sua linearidade, noção por meio da qual compreendemos o fenômeno de continuidade, quando há organização seqüencial dos tópicos e o fenômeno de descontinuidade, marcado pela perturbação na seqüencialidade. O plano vertical, por sua vez, diz respeito às relações de interdependência existentes entre um determinado tópico e suas subdivisões. Em um trabalho posterior, a autora reporta-se aos dois planos mencionados da seguinte forma: "a organização horizontal corresponde à progressão dos tópicos no desenrolar do diálogo", enquanto a organização vertical é "decorrente de uma sucessiva especificação do assunto em pauta, até os limites das necessidades interacionais" (JUBRAN, 1994, p. 62). 
Além de centração e organicidade, outra propriedade do tópico é a segmentação. Ela consiste na delimitação dos vários segmentos ou porções tópicas, intuitivamente identificadas pelos falantes, na medida em que há, na fala, marcas desta delimitação tópica, mas que nem sempre constituem um critério absoluto, pois são facultativos, multifuncionais e co-ocorrentes.

Cabe acrescentar que os discursos falado e escrito apresentam diferenças no que diz respeito à organização de desenvolvimentos tópicos. A conversação desenvolve a dinâmica tópica interativa (ou seja, com monitoramento local), ao passo que o texto escrito segue um processo enunciativo mais calculado, pois as suposições e inferências possibilitam um planejamento de maior abrangência. Essa diferença decorre das diferentes condições de produção de ambas as modalidades de exteriorização lingüística: a oralidade ocorre em tempo real, ao passo que existe na escrita uma defasagem temporal entre a produção e a recepção.

\subsection{Formas de continuidade tópica}

Keenan e Schiffelin (1976) definem duas formas de continuidade tópica: a colaborativa e a incorporativa. No primeiro caso, a continuidade é estabelecida de forma estrita, ou seja, mantémse rigorosamente o mesmo tópico discursivo em dois enunciados sucessivos ou numa seqüência de enunciados:

(01) Doc. você falou em:: carreira... boa para a mulher né?

L2 ahn ahn

Doc. que tipo de carreira... fora essa... seriam digamos conveniente...

L2 Olha ab o til o til ab o especificamente o tipo de carreira ab en acho que isso seria qual/ qualquer uma ( ) quer dizer:: o o::

lado... o lado de ciências mais human/

ah de o lado bumano o ou de::... ciências

exatas como chamava-se no MEU tem::pó

(...)

(NURC/SP, 360, 1. 646-654) 
No exemplo anterior, a informante L2 responde à documentadora com a retomada precisa do subtópico introduzido por esta última ("carreiras boas para a mulher").

Já na continuidade incorporativa, a seqüência de tópicos é estabelecida de forma menos rigorosa, já que se baseia em pressupostos e inferências, não na retomada estrita do tópico:

(02) (A informante discorre acerca da produção cinematográfica nacional).

L1 mas agora estão dizendo que estão passando aí um filme muito bom $O$ Predileto não é?... você ouviu falar?

L2 é ( )

L1 diz que é um filme também nesta linha brasileira... até achei graça uma amiga minha disse... "eu gostei muito do filme... porque ele tem sobretudo... uma cafonice bem brasileira ((rindo))...

L2 ah

L1 retratando determinado mundo "... en acho que é muito bom... que o Brasil em literatura pelos seus escritores há bastante tempo... já deixou de ter o seu cordão umbilical... preso à Europa... e.:: e todo o::... toda a América Latina já se desprendeu... desse cordão umbilical farendo uma literatura muito... da terra muito do homem... nativo(...)

(NURC/SP, 333, 1. 653-668)

A informante está tratando da produção cinematográfica nacional e, no trecho transcrito, menciona o filme $O$ Predileto. A seguir, ela afirma que o Brasil e a América já alcançaram autonomia no plano cultural, e justifica essa afirmativa com base na literatura. Esse fato significa que existe continuidade entre os dois assuntos, mas ela só se estabelece em termos bem abrangentes, a partir do conhecimento de mundo das -interlocutoras, pois ambos os assuntos relacionam-se com o tópico genérico produção cultural. 


\section{A Expansão do Tópico}

\subsection{Procedimentos discursivos de expansão do tópico}

Os informantes utilizam procedimentos variados para a expansão do tópico. Esses procedimentos correspondem a diferentes formas de atuação e participação dos interlocutores e são realizados com dupla finalidade: reforçar a focalização do tópico em andamento, por meio do fornecimento de informações complementares ou adicionais, e fornecer pistas de contextualização que venham a situar os assuntos tratados no universo cognitivo-conceitual dos interlocutores. são citados a seguir.

Os procedimentos de expansão do tópico mais freqüentes

\subsubsection{Explicitação do tópico}

Trata-se do procedimento de expansão ou desenvolvimento do tópico mediante o fornecimento de informações complementares ou esclarecimentos. A explicitação pode assumir três feições distintas:

- explicitação do fato:

(03) (A informante trata da sua rotina de atividades domésticas).

L2 (...) a gente vive de motorista o dia inTEIRO mas o dia inTEIRO... uma corrdia BÁRbara e leva na escola ( ) e vais buscar... os dois estão na escola de manhã-porque eu trabalho

de manhã--... então eu os levo para a escola

... e vou trabalhar... depois saio na hora de buscá-los... aí depois tem natação segunda quarta e sexta... os dois... das duas às três... tem que

... saio meio-dia da escola (então) tem que vir correndo... almoçar depressa para dar tempo de digestão para poder entrar na escola às duas horas (...)

(NURC/SP, 360, 1. 93-102) 
A informante cita o fato de ser ela a motorista da família e trata da rotina diária, como forma de assinalar que esse realmente é o papel a ela atribuído na divisão de trabalho do lar.

- explicitação das características:

(04) (O informante trata da alma do Ceará).

L1 (...) diz que no Ceará a coisa é maravilhosa né?... além do clima ser:: gosTOso né?... sempre agraDÁvel.. diz que as noites

cearenses são uma delícia [não sei se já tiveram oportunidade

Doc. nunca]

L1 e realmente dir. que lá... a LUa... pelo fato de estar próxima da linha do Equador

é muito grande... então realmente lá tem aquelas noites praTEadas mesmo... a água do mar... diz que fica PREta... em contraste com a areia que fica muito branca em virtude da... claridade da lua né?... diz que lá é bastante agradável sabe?... e o clima inclusive é muito mais regular que aqui (...)

(NURC/SP, 062, 1.123-136)

(O trecho entre colchetes não faz parte da expansão tópica, por constituir uma digressão).

O locutor cita as características das noites cearenses, como forma de expandir o subtópico "as qualidades do clima do Ceará". 
- explicitação de conceitos:

(05) Doc. e como vocês vêem a evolução da TV?

L1 a evolução da TV... estou vendo a evolução

da TV muito presa a singularidades brasileiras... e não se pode mesmo... analisá-lo fora do contexto brasileiro... então quando se pede à TV... a altura o nivel... de uma televisão eu/ européia... meu Deus mas porque só a televisão tem que ter esta altura... quando as outras... os outros setores estão ainda claudicando... sob diversos aspectos?

(NURC/SP, 333, 1. 301-309)

No exemplo anterior, a informante discute o conceito "evolução da TV" e, ao mesmo tempo, emite a sua opinião acerca do nível da TV brasileira.

A explicitação do tópico, em suas diversas modalidades, tem uma nítida feição contextualizadora, à medida que contribui para a criação de uma base de conhecimentos partilhados entre os interlocutores. Aliás, os diversos procedimentos de expansão do tópico exercem essa função contextualizadora, já que todos eles, de qualquer forma, contribuem para explicitar ou esclarecer o tópico.

Os procedimentos de explicitação fluem diretamente do tópico em andamento e, assim, geralmente não são introduzidos por marcadores conversacionais. Em apenas 14\% das ocorrências verificase a presença de marcadores (acontece que, você vê que, veja você, diz que) que, na maioria dos casos, exerce outra função (sobretudo o envolvimento dos ouvintes) além de assinalar a expansão do tópico.

\subsubsection{Exemplo e analogia}

Esse segundo procedimento consiste na alusão a casos particulares, representativos de uma dada situação. Veja-se o exemplo a seguir: 
(06) (Os informantes discutem os problemas advindos do crescimento, e a possibilidade de elas ficarem paralisadas).

L1 (...) me parece que não não deve paralisar porque não tem... caso análogo (na história)... você tem por exemplo (Tóquio) para fazer você conforme... o azar tem você fica quatro horas paralisado num trânsito... (la:: qualquer)

L2 mas nem por isso deixa de ir ( )

L1 [mas isso é relativo né? você não pode ter:: não é global isso né? então sei lá digamos uma regiãozinha ali:.... os que não estão acostumados com a cidade pum se mete no trânsito e se se se (ficam)... talvez. até:: em São Paulo... eu nunca pego o trânsito... correto?

(NURC/SP, 343, 1. 460-471)

A exemplificação torna o tópico em andamento mais concreto e mais acessível ao interlocutor, por meio da retomada de um caso particular. No trecho citado, esse procedimento tem um valor argumentativo, já que o locutor contrapõe o seu ponto de vista (que as cidades não vão ficar paralisadas) ao de sua interlocutora. Essa função concretizadora confere aos exemplos um nítido caráter contextualizador, pois, por meio deles, o locutor dá à sua opinião maiores possibilidades de ser aceita pelo interlocutor. Com isso, verificase que o exemplo tem um nítido caráter interacional já que se volta para o interlocutor.

Esse mesmo caráter interacional também se manifesta nos casos em que a exemplificação assume a feição de alusão a autores e obras: 
(07) L2 que que você vê esse pessoal de teatro... para mim é:: é a classe mais sofrida que tem... entende? Para mim ele esses daí... se dedicam entende? EU acho esse é o meu ponto de vista eles... investimento deles... é como você jogar na Bolsa talvez pior até entende?... o:: rapaz aí o Altair Lima que montou Hair ele levantou uma nota... ele... agora... você pergunta assim o artista ou você perguntaria o produtor?

Doc. não mas... em geral tudo... então se você quisesse falar se você faz uma distinção você pode falar dos dois (no caso)...

L2 Você vê o:: o:: o Altair Lima ele é... arriscon está certo... ele arriscon ele... pôs tudo:: segundo declaração dele não sei se são demagógicas ou não ele pôs... tudo que ele tinha na na montagem da peca Hair... poderia chegar aqui... não vai mon/ não vão... a censura não deixa montar e está acabado... que ele aplicon ele vai para o... sain muito bem... dizem que nessa que ele montou agora já não está... tendo a mesma aceitação que que teve o Hair... Jesus Cristo Superstar entende?... então que o que que você vê? O individuo joga arrisca

[... você vê é é mais fácil fechar teatro que abrir... hoje em dia fecha mais teatro do que abre...]

(NURC/SP, 062, 1. 1279-1301)

(O trecho entre colchetes não faz parte da alusão, e constitui um caso de expansão por acréscimo de informações adicionais, modalidade que será discutida num dos próximos itens).

A alusão ao espetáculo Hair e ao produtor Altair Lima, além da função argumentativa e contextualizadora, permite ao informante indicar, de modo explícito, que ele faz afirmações bem embasadas, com o devido conhecimento do assunto em andamento. Com efeito, por meio da alusão a Hair, o locutor justifica a afirmação anterior (o investimento em teatro é de alto risco) de modo consistente, pois o referido espetáculo teve, na época em que foi exibido, uma ampla repercussão. Este é, pois, de um procedimento que permite ao interlocutor construir uma imagem bastante positiva de si mesmo e, assim, obter uma reação favorável das partes do seu interlocutor. 
Acrescente-se que, entre os casos de exemplificação ou alusão, predominam largamente as ocorrências introduzidas por marcadores conversacionais: em $81 \%$ dos casos verifica-se a presença de marcadores (por exemplo, um exemplo é, você tem por exemplo, você vê e assemelhados).

\subsubsection{Justificativa ou relações causais}

De forma genérica, todos os procedimentos de expansão justificam as afirmações do locutor, particularmente quando se trata de temas polêmicos. Em alguns casos, porém, o locutor sente a necessidade de justificar, de forma explícita, uma afirmação ou de indicar a causa/conseqüência de um fato. É o que se verifica no exemplo a seguir, no qual o informante explica por que o método "braçal" foi substituído pelo computador no cálculo de estruturas:

(08) L1 Acontece o seguinte... quando eu estudei éh::... tive que... éh:: aprender uma série de métodos de... cálculo dimensionamento de pontes

L2 ahn

L1 agora vários desses... vários desses métodos não não não são mais necessários... não se aprende porque:: eles estão suplantados né? você não precisa mais calcular o compul - computador calcula... e cada vez. mais o computador adquire... uma:: capacidade de calcular as coisas... não é que ELE adquire ( ) já lançaram... computadores mais aperfeicoados certo?

L2 ahn ahn

L1 então eu peguei uma fase em que estava mais ou menos bom:: sei lá eu achei bom::... que eu aprendi bastan::te... como fazer eu mesmo... e depois aprendi como fazer pelo computador... então en sabia dos dois jeitos né? como eu teria que fazer...

L2 ahn ahn

L1 Utilizando a matemática e... como en teria que fazer utilizando o computador

L2 ahn ahn 
L1 agora não é simples você usar computador... como não é simples calcular... então chega um ponto que você não pode fazer os dois... ( ) um dos dois... então se tem aluno de pontes... às vezes eu fioo em dúvida se ensino... método por computador... ou método... braçal que seria ele fazer... eu não tenho tempo para para ensinar os dois ele não tem tempo para aprender os dois

L2 ahn quer dizer ensinar só o braçal né?

(NURC/ SP, 343, l. 838-886)

Na primeira ocorrência, o locutor justifica por que já não se utilizam os métodos de cálculo pela matemática. No segundo enunciado destacado, ficam explícitas as conseqüências de ele (0 informante) ter aprendido dos dois modos. Finalmente, no terceiro trecho, ficam claras as conseqüências da existência desses dois métodos. Veja o exemplo a seguir:

(09) L1 Muitas pessoas têm viajado ultimamente ultimamente eu não tenho vajado-- ... tem dito por exemplo quem em va/ diversos países da Europa e televisão esta muito ruim... porque a televisão sendo estatal ela é muito uniformiZA da... não há:: espetáculos diversificados o telespectador... o::: fica sempre... preso... a filmes ou a conferências...

(NURC/ SP, 333, 1. 311-315)

A locutora justifica o fato de a televisão européia não ter qualidade de programação com a alusão à falta de opções apresentadas ao telespectador.

A expansão por justificativa ou relações causais tem, como os processos já focalizados, um papel interacional, já que contribui para a criação de um contexto comum, partilhado entre os interlocutores. Além disso, esse procedimento contribui para a construção de uma imagem positiva do locutor: ao embasar suas afirmações em dados concretos, que se tornam mutamente acessíveis, ele busca ser reconhecido como alguém que domina 0 assunto em pauta e não faz afirmações sem fundamento. Essa característica 
aproxima a expansão por justificativa da alusão a exemplos e, do mesmo modo, verifica-se que ambos os procedimentos exercem um nítido papel argumentativo.

O utra semelhança entre os procedimentos citados no parágrafo anterior é o fato de, em ambos, predominarem largamente as ocorrências introduzidas por marcadores conversacionais. No caso da justificativa, em $87 \%$ das ocorrências verifica-se a presença de marcadores de valor coesivo ou textual (então, daí, porque é que, entre outros).

\subsection{Opinião pessoal ou avaliação}

Neste caso, a expansão do tópico ocorre por meio de um juízo ou opinião pessoal, os quais, com freqüência, representam uma avaliação do assunto em pauta:

(10) (A informante do seu relacionamento inicial com a televisão).

L1 (...) houve uma época na minha vida que a literatura: me fazia prestar muita atenção... e eu queria era uma fuga... então a minha fuga... era me deitar na cama... ligar 0:: receptor e ficar vendo... ficar vendo... e:: aí eu comecei a prestar atenção naquela tela pequena.. vi... não só que já se fazia muita oisa boa e também muita coisa ruim é daro... mas:: vi também todas as possibilidades... que aquele vé́culo... ensejava e que estavam ali laT E N tes para serem aproveitados...

(NURC/ SP, 333, l. 13-21)

No exemplo anterior, ocorre um deslocamento parcial do tópico, uma forma de continuidade menos estrita, pois o enfoque deixa de ser a televisão em si e recai na opinião da informante acerca das potencialidades desse veículo. Existe, pois, uma cisão (parcial) do foco, o qual passa a incidir, a um só tempo, sobre o assunto em si (a televisão) e sobre o locutor.

Fica claro, porém, que não há ruptura tópica, mas uma manifestação da subjetividade da própria informante. Apesar desse 
caráter subjetivo, verifica-se que a opinião pessoal possui também um caráter contextualizador e evidencia a relevância do assunto em questão: ao tratar das potencialidades da TV, a informante ressalta a importância desse veículo.

No exemplo anterior, a informante introduz espontaneamente uma opinião. Já no próximo exemplo, verifica-se que essa manifestação decorre de um pedido explícito do outro interlocutor:

(11) (O s informantes discutem a irregularidade do clima de São Paulo)

L1 (...) a gente às vezes tem vontade né? de fugir um pouco desse clima né? que que você acha colega?...

L2 A cho que seria 0 ideal isso... se a gente tivesse condição de sempre estar::... procurando um dima melhor você vê o Rio de Janeiro ... em pleno inverno nós estamos às vezes no Rio de Janeiro você ouve aí anteontem eu estava lendo trinta e dois graus (...)

(NURC/ SP, 062, 1. 135-143)

No exemplo anterior, o informante corrobora a sua opinião com um exemplo (o clima do Rio de Janeiro).

O sjuízos e opiniões vêm sempre introduzidos por certos marcadores, denominados prefaciadores de opinião. 0 prefaciador de opinião mais freqüente é prototípico é (eu) acho que, mas outros podem ser citados: eu vejo, eu creio, eu penso...

Os prefaciadores de opinião são normalmente representados por verbos na primeira pessoa, com os quais se introduz mais diretamente a subjetividade no discurso e se assinala que o foco passa a incidir não só sobre o tópico, mas também sobre 0 próprio locutor.

Cabe lembrar que (eu) acho que nem sempre tem por função prefaciar opiniões ou introduzir juízos ou avaliações. Em exemplos semelhantes ao próximo, a função mais evidente do referido marcador é a de atenuador. 
(12) D oc. e quando vocês quiseram... escolher uma carreira... o que as levou a escolher a

carreira?

L2 a minha eu acho... eu não tenho certeza para julgar mas eu acho que foi incutida... meu pai... foi 0 um::... era militar:: mas a vocação dele era ter sido... advogado então ele vivia dizendo isso... e eu tenho a impressão eu não posso dizer porque é difícil (...)

(NURC/ SP, 360, l. 1511-1517)

As duas ocorrências de eu acho não introduzem propriamente uma opinião, mas indicam, de forma explícita, a falta de convicção da locutora que, por meio delas, sinaliza que não assume responsabilidade plena por aquilo que vai ser dito.

\subsubsection{Objeção ou ressalva}

Incluem-se neste item os casos em que um dos interlocutores dá continuidade ao tópico em andamento por meio da manifestação de um juízo ou ponto de vista contrário ao do seu interlocutor:

(13) (O s informantes discutem questões referentes a emprego e trabalho)

L1 Então o desen/ o desenvolvimento é bom porque ele dá chance de emprego para mais gente...

L2 mas você está pegando uma coisinh::nhá assim sabe? um cara que esteja desempregado também eu posso... usar 0 mesmo exemplo num num sentido contrário... o cara que está desempregado porque não consegue se empregar né? na verdade não quer... ou um outro que:: assim... muito bem empregado executivo chefe de empresa e tal mas cheio das neuroses dele... eu não sei qual está melhor...

L1 então você tem que abstrair desse aspecto porque você pode ter ambos os ca::sos você tem que pegar na média esquecendo esse aspecto particular... 
L2 E mas aí:: é o tal negócio eu não me preocupo muito com a média... pra mim interessa:: 0:: indivíduo né?... salvação individual então eu pensar... como é que está essa média como é que está aquela... como é que está a ou/ ... ( ) realmente me faltam dados né? de eu não procurar esses dados de eu não me tocar muito... e ver::...

L1 é eu às vezes me preocupo com... digamos com a média pelo seguinte... eu me preocupo com o que que eu estou contribuindo com o bem da méida ou não... porque porque eu pego e calculo uma coisa que chegou a mim... e de mim vai para outros

(NURC/ SP, 343, l. 555-580)

L1 afirma que o desenvolvimento é bom porque assegura emprego para as pessoas, mas L2 refuta essa colocação, e fala que nem sempre a pessoa empregada é feliz. L1 contradiz essa colocação e afirma que é preciso preocupar-se com a média, mas L2, sendo psicóloga, afirma que é preciso preocupar-se com o indivíduo.

Verifica-se, assim, que não há continuidade estrita entre as falas, pois a objeção ou a ressalva implicam uma mudança parcial de enfoque. Existe, por certo, a continuidade, mas ela ocorre em termos abrangentes (nesse caso, em referência ao tópico emprego.

0 mesmo ocorre no exemplo a seguir, em que L1 recusa a pertinência da comparação entre 0 médico clínico-geral e 0 engenheiro-civil:

(14) L1 (...) mas pega um clínico geral... por incrível que pareça é o que mais... estuda... certo? ... é o que tem a MAIOR especialização... em compensação é o mais injustiçado... pediatria...

L2 ele ele estaria dentro do caso do engenheiro civil então o clínico geral assim de::... em termo não de estudo digamos mas de... de campo de serviço?

L1 se bem que o engenheiro hoje está bem hein meu querido... ahn?

L2 ah mas tem engenheiro civil sobrando aí hein V. ((risos)) 
L1 com todas essas facilidades do BNH aí... está todo mundo comprando casa própria... então os engenheiros estão levantando prédios aí que não acaba mais... você não está vendo isso?

(NURC/ SP, 062, 1. 673-686)

L2 faz uma analogia ente o clínico-geral e o engenheirocivil, mas L1 recusa essa aproximação, afirmando que, em relação ao emprego, a situação deste último profissional é positiva. D a mesma forma que no exemplo anterior, não há continuidade estrita entre as falas de um interlocutor em relação à do outro, mas apenas entre os turnos do mesmo interlocutor.

98\% dos casos de objeção ou ressalva são introduzidos por um marcador conversacional de valor argumentativo. M as constitui o marcador prototípico dessa modalidade de continuidade tópica, no entanto outros também aparecem (porém, se bem que...).

\subsection{Comentários acerca dos Procedimentos de Expansão do Tópico}

\subsubsection{Procedimentos de expansão e formas de continuidade tópica}

Os procedimentos de expansão dividem-se em dois grupos, quando associados às formas de continuidade tópica: na explicitação (em suas diversas formas), na exemplificação ou analogia, e nas relações causais, a continuidade do assunto é estrita, pois nelas geralmente ocorre a retomada do mesmo tópico (continuidade colaborativa). Já nas opiniões e juízos, ou nas objeções e ressalvas não existe necessariamente a retomada do mesmo tópico, já que nelas 0 enfoque se desloca do assunto em si para a esfera da subjetividade, manifestada pelo modo de ver ou sentir do locutor ou, ainda, por um ponto de vista divergente (continuidade incorporativa).

A continuidade do assunto em termos estritos constitui a forma de expansão mais nítida e evidente, pois nela ocorre 0 desdobramento do tópico. Com esse desdobramento, o locutor procura evidenciar a pertinência do tópico e do enfoque por ele atribuído e, do mesmo modo, busca inserir o assunto tratado no universo cognitivo 
e conceitual dos demais interlocutores. Essa forma de continuidade possibilita o enquadramento do tópico e, por isso, é a mais freqüente, como será discutido no próximo item desta exposição.

Nas formas de continuidade incorporativa não há propriamente um desdobramento do assunto, mas a exposição da opinião ou do ponto de vista do locutor. Por isso mesmo, essas formas são menos freqüentes, e correspondem a momentos específicos do desenvolvimento da interação, nos quais aflora, de forma mais direta, a subjetividade dos interlocutores. 0 tópico não se expande, digamos, de dentro para fora, de modo que o papel contextualizador dos procedimentos que manifestam a continuidade incorporativa é menos nítido.

\subsubsection{Distribuição dos procedimentos de expansão}

0 quadro a seguir expõe os percentuais referentes às diversas formas de expansão do tópico.

Quadro 1 - Modalidade de expansão do tópico (dados percentuais)

\begin{tabular}{||l|l||}
\hline \hline \multicolumn{1}{|c||}{ MODALIDADE } & \% \\
\hline Explicitação & 58 \\
\hline Exemplificacão & 16 \\
\hline Relações causais & 12 \\
\hline O bjeção ou ressalva & 06 \\
\hline O pinião & 08 \\
\hline \hline
\end{tabular}

A modalidade de expansão mais freqüente é representada pelas diversas formas de explicitação. Esse predomínio é devido ao fato de ser ela a que permite - de forma mais direta - a criação de um espaço comum partilhado pelos interlocutores. Usando-se uma imagem concreta, pode-se admitir que a explicitação corresponde ao desembrulhar de um pacote, e isso permite colocar em evidência as características de um ser, os desdobramentos de um conceito ou as particularidades de um fato. Essa evidenciação ilumina o tópico e permite inseri-lo no conhecimento prévio de cada interlocutor e no contexto partilhado que se cria no momento da interação verbal. 
Esse mesmo papel interacional pode ser encontrado no fato de a expansão reforçar o enquadramento estabelecido pelos interlocutores em relação ao tópico em andamento. Aliás, dentro da dinâmica do texto conversacional, esse enquadramento é sempre necessário, como forma de mostrar que o enfoque é pertinente e 0 tópico não está esgotado.

O papel de contextualização e enquadramento também pertence à exemplificação e às relações causais. Na primeira, esse papel é exercido pela alusão a um caso particular; já nas relações causais, é a explicitação da causa e da conseqüência que permite a inserção do tópico no universo cognitivo dos interlocutores.

Esse papel contextualizador faz com que a explicitação, as relações causais e a menção de exemplos correspondam a efeitos contextuais, conceito discutido por Sperber e Wilson (1986, p. 109 seq.). Segundo eles, os efeitos contextuais permitem a interação entre informações velhas e novas, de modo que entre ambas se cria uma implicação. Para os autores, existem duas espécies de efeitos contextuais: a primeira são aqueles procedimentos que fornecem informações adicionais e, assim, reforçam o já mencionado; a outra espécie é representada pelos efeitos contrários ao que foi dito. Ora, três modalidades de expansão citadas encaixam-se nos efeitos contextuais do primeiro tipo, já que enfatizam o tópico em andamento e fazem com que eles não sofram qualquer esvaziamento. Esse reforço, lembrese, não ocorre de forma aleatória, já ele corresponde à inserção das informações no universo partilhado pelos interlocutores.

As modalidades de expansão ligadas à continuidade incorporativa (opiniões; objeções ou ressalvas) correspondem ao segundo tipo de efeitos contextuais, pois com eles o locutor busca redirecionar o que foi dito. No caso da objeção, esse redirecionamento ébastante nítido, mas ele se verifica também na manifestação de opiniões, na qual os locutores deixam de tratar do assunto em si, para dizerem 0 que pensam do tópico em si. Por isso mesmo, o papel desses procedimentos na contextualização e no estabelecimento da relevância é mais limitado que nos outros procedimentos. Cabe lembrar que, nesses dois procedimentos, o enfoque não é propriamente 0 assunto, mas o interlocutor ou, mais precisamente, o ponto de vista do interlocutor acerca do que está sendo tratado. 


\section{Comentários Conclusivos}

0 estudo dos procedimentos de expansão do tópico confirma, inicialmente, que o tópico discursivo constitui, de fato, a razão principal do desenvolvimento do processo interacional. Com efeito, os interlocutores usam esses procedimentos com uma finalidade interacional, qual seja, fazer com que 0 assunto discutido adquira a relevância necessária e seja inserido no universo cognitivo e conceitual dos interlocutores. Aliás, o predomínio do desenvolvimento por explicitação evidencia o papel contextualizador desses procedimentos. O s outros procedimentos ou apresentam essa mesma função contextualizadora ou assinalam, de uma forma mais direta, a presença do interlocutor.

Além disso, verifica-se que o desenvolvimento do tópico não é planejado previamente, já que o uso dos diversos procedimentos flui do assunto tratado e das reações dos interlocutores. Assim, fica justificado o predomínio dos procedimentos de explicitação, já que são eles que efetuam, de modo mais direto eimediato, a contextualização dos assuntos tratados. D o mesmo modo se explica o pequeno número de ocorrências ligadas à continuidade incorporativa; estas, por serem fracamente contextualizadoras, figuram apenas em trechos nos quais 0 desenvolvimento do tópico cede lugar às manifestações de caráter pessoal.

\section{Referências Bibliográficas}

BRAIT, Beth. $O$ processo interacional. In: PRETI, Dino (O rg.). Análise de textos orais. São Paulo: Humanitas, 1993. p. 189-214.

BROWN, Gillian; Y ULE, George. Discourse Analysis. London: Oxford Press, 1983.

CASTILHO, A taliba Teixeira de; PRETI, Dino (O rgs.). A linguagem falada culta na cidade de São Paulo. v. II - D iálogos entre dois informantes. São Paulo: T. A. Q ueiroz/ FAPE SP, 1987. 
FÁVERO, Leonor Lopes. Coesão e coerência textuais. 7. ed. São Paulo: Ática, 1999.

JUBRAN, Clélia Cândida Spinardi et al. O rganização tópica da conversação. In: ILARI, Rodolfo (O rg.). Gramática do português falado. v. II. Níveis de análise lingüística. Campinas: Ed. UNICAMP/ FAPESP, 1993. p. 357-397.

. Inserção: um fenômeno de descontinuidade na organização tópica. In: CASTILHO, Ataliba Teixeira de. (O rg.). Gramática do português falado. v. III - As abordagens. Campinas: Ed. UNICAMP/ FAPESP, 1994. p. 61-74.

KEENAN, Elinor Ochs; SCHIEFFELIN, Bambi B. Topic as a discourse notion: a study of topic in the conversations of children and adults. In: LI, Charles N. (Ed.) Subject and Topic. London/ New York: Academic Press, 1976. p. 337-384.

MARCUSCHI, Luiz Antônio. Análise da conversação. São Paulo: Ática, 1986.

SPERBER, D an; WILSO N, D eidre. Relevance. Communication and cognition. Cambridge, Massachusets: Harvard University Press, 1986. 